\title{
蘇聯數淟工作者們 在數理哲翼方面的研究
}

\section{A. 雅諾夫斯卡雅著(蘇聯數學三十年) 關朢直譯}

\section{$(-)$}

在蘇眑,在數理折舁方面,工作開始於熟習馬 列主義的經典著作，和批棓唯心主掌的资產階䄲 數理哲學。首先諭述的是關於數學的主題問題的 研究，和數祭在科舉體系中的地位, 以及與這些有 機聯繫着的、關於在數學中形式的和讋登的雖輯 的問題。

如所週知,關於数學主題有一些不同的定军。 其中有一些人一概否認在這種學閣中有特殊的主 題。很多人一都是當代資産階級的哲學工作者 和数興工作者們一一着上了唯心主㼁的外本，亚 或多或少地同意於相當篇人所知的說法：把數舉 定義做不知道所談何事、也不知道所㒛者苴㒀的 科嶨。A・海庭格在他的 “數祭基礎的研究概論” 一書中論及“當代主流各方面的代表 人物對於數 學應用於認識察在”的看法時, 曾並非無理由 地 詒:“在一方面，他們彼此間是同意的一一而且在 現在可以說差不多是全體數舅工作者門的一致意 見一一䛱篇純料数學的命題毫不論及實在”。促海 庭格說“营不多是全體數學工作者們的一玫意見，

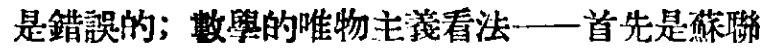
数舉工作者們的各祭派代表者一一並不持造種意 見。他們同意於恩格斯的定義,認篇數學是研究物 啠世界的空間形式和數量關係的科學。與這定窂 相聯擊着的著名困難是基於下面的理由：在數舆 中有些部門既不談論數, 也不談論形, 只是以形 而上的方式存在着。C-A - 雅諾夫斯卡雅在第一

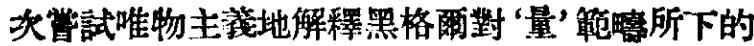

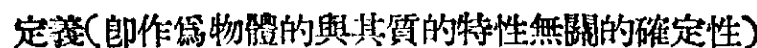
時，把物啠筫在的量留係理解篦在具有最不同本 性的物䯠間可能保在的關係:電子、原子、以至紙

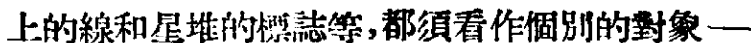
造亚汥有對原問題給出圆满的解答。一方面說明 了各數學部門的基本上不同解釋的 可能性，以
及由此對於科學種種不同領域的可應用性; 另一 方面, 數學方法對於研究自然現象或社會生活的 最本質的方面的不光足性。但她汥有注意到下面 的情形：就是數學部門的形式公理學一一容許一 些本質上不相同的解釋一一的黛立如果不用算術 的㠍立根本是不可能的, 而在算術中則數和諸数 間彼此的關係只有一意的、確定的酒義, 正像 (此 如說) 價值在政治經济學中一樣。如此, 數藇的固

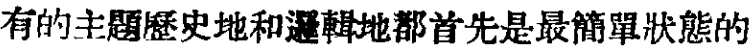
空間形式和數量關係，也就是形和數。数學中所研 究的其他一切空間形式和數量關係，都是以讋證 的称展程序而由此育生的。 $\mathrm{A} \cdot \mathrm{H} \cdot$ 廊勤莫郭洛夫 （〔2]）在:其䉆蔡聯大百科全書所寫的文章中極清 楚地說明了造種觀點。

$A \cdot H \cdot$ 厗勒莫郭洛夫完全從恩格斯的定義州

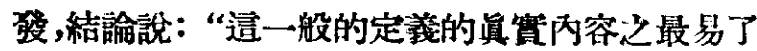
解是依其墢生的次序而考察數學中的各基本概念

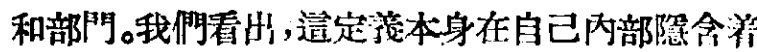

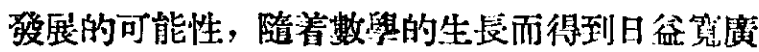

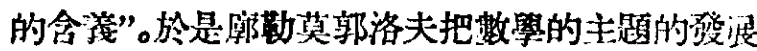

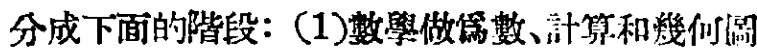

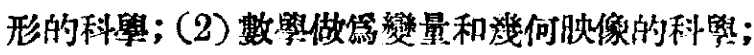
（3）数學做第凟在世界的最一般性的數量與空閒 形式的科學。

\section{(二)}

唯心主義哲學家們企圖把数學“從外在世界 的統治下解放出來 (如昂利・潘加梖)，或依康德 企圖把數學建築在“純直觀的思考”的材料之.上. (直

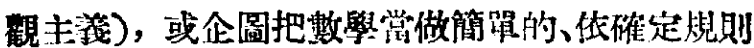
而推演的一惟公式(形式主義); 與這些企圖相聯 慗着的数㪄基礎的危機只是在第一次世界大戰之 媵才到達了最尖銳的地步。無怪乎列蜜的“唯物論 與經驗批判論 書中遖接 對數理折學問題只零星

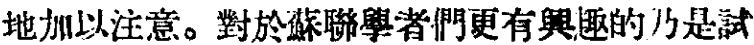


把列察對物理學危機的原因及本質所指似的特徵 磼用於數學基碟的危機上。諭数學基礎的危機與 批評其中幾程江代由凟库階級数理哲學家們所領 荨的唯心主義的方向者,有一系列的著作，其著者 包括有 $\mathrm{B} \cdot$ и 1]、[3]、[4]), B・H・莫洛德希 $([1]), C \cdot A \cdot$ 雅諾 夫斯卡雅([2]、[3]、[4])等。莫斯科國立大罢的數 學系数授與其合作者們在列察的 '唯物 諭 與經驗 批判論” 二十五䓢年紀念喘了一部 數理哲學諭文 集(註一)。著者們提出的任䅂是“指出近世數學的 特徵，揭示其基礎危機的原因和本質，阔明在近世 数學底哲學中的黨性鬥争”。如所預期, 列察對於 物理學危機的本質和基本踚廊所指出的特徽完全 可用於数學基佬的危機上去。B・ H・格利汝科於 是着重地指出:“世界大戰後資本主義社會整個危

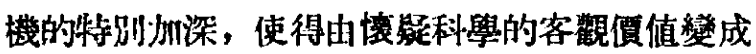

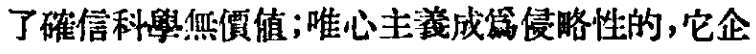
圖把科學蓝其一切問題與方法都征服。”

\section{(三)}

蘇聯和聯共黨對於馬克思、恩格斯的遗產之

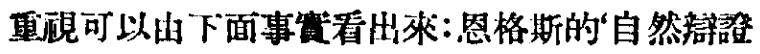
法”, 和馬克思的 “数學篗記” 都是在蘇聯首次㑁版 的 (註二)。馬克思数學筆記的校釋和翻譯是由數

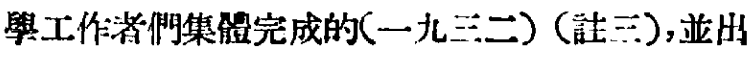
版了一系列的諭文 $(\mathrm{B} \cdot \mathrm{и} \cdot$ 格利败科 $[1], \Omega \cdot \Pi \cdot$

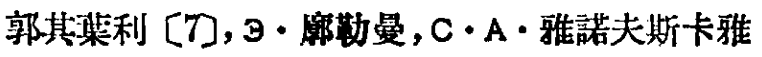
$[6],[7],[8])$ 。

$C \cdot A \cdot$ 雅諾夫断卡雅的論文(〔7 的敍达, 她企间說明馬克思關於微分學基礎問題

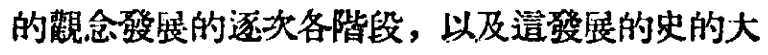
㮶(註四), 也引澄了一些点思更早期的著作草 稿, 後者乃是後來由他所定形並送恩格斯校看的 著作的淮借材料。

$B \cdot H \cdot$ 格利汶科的論文(見詰 [1])特别討論 了馬克思把微分看做逜算符號的觀點。

馬克思數算筆記的出版特别清楚地證明了下 面的事筧，郎只有在用列學和斯大林發住了的態 度才可能把畺望的理解應用到数舉上去，戈可能

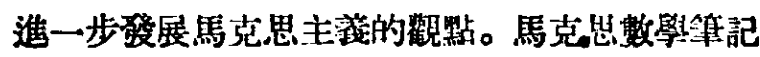
中包含着以其特有的創作性而斯異地應用讋證法 去解让微分學集基問題的学試。但在這方面，馬克

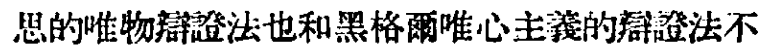

同!依黑格雨的観點，掊證法一般地不能應用於数

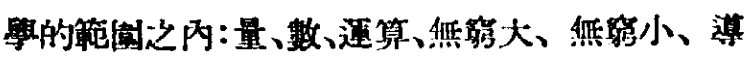
式、微分等只是在其唯心主军指學的系統中才能

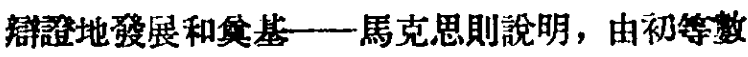

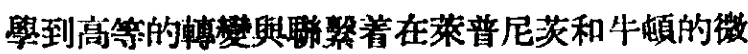

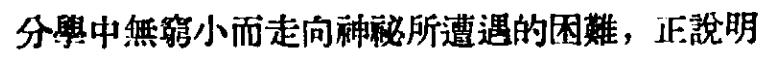

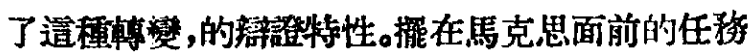
乃是藉助唯物讋證法去克服造種困難；道方法馬 克思用之於數鼠基礎上和他用之於“資本諭一檬。

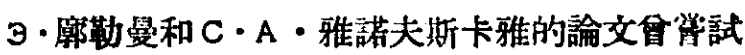
着墽明馬克思的唯物讋證法和黑格爾的唯心主军

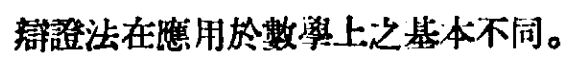

在討諭 $\Gamma \cdot \Phi \cdot$-阿列克:德洛夫“西殹哲奥史” 一書時, A-A - 日丹諾大曾为重地指出那種處理 哲學史(與其他科學的歴史)的不正確的、非馬克

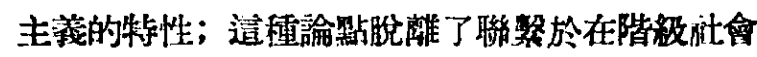

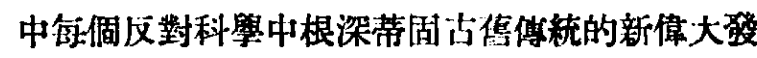

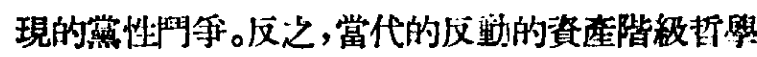
工作者和科學史工作者企圖以各種方法磨平自然

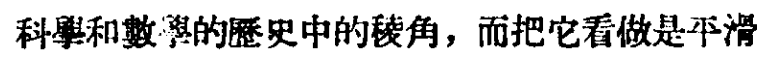
的演進程序，在一個偉大的發現或理論之挠跟着

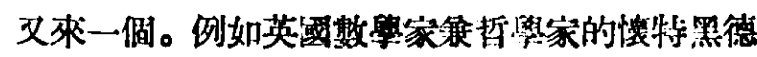
認侮從中世紀的繁瑄哲學到新時代科學的轉變只

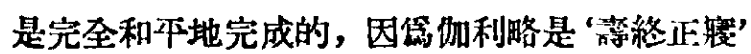
的,而卓爾達諾・布魯諾的死有 ‘進步的’、“象徴的, 意俄，因偊他蓝沒有藏有勇敢的新概念，而只 “不

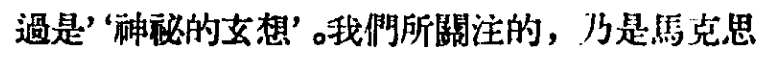
在其數舉筆記中特別注重地指出在初起時代環繇

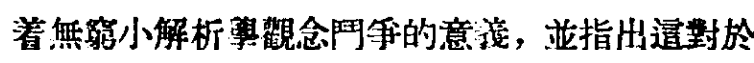
境新的鋪通路万是必須的。馬克思腺道: “他們自 已(微皘分的創始渚們一一本文原著者註)相信道

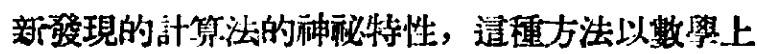
正面不正確的途徑得出了正確的結果（而在烧何 學的應用方面简遖是管人的結焽)。如此他們自己

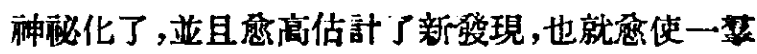
老的正統派数學家們症狂，從而刺激起来一片敵 意的叫喊,在對数學無所知的人草中也如此喊,㯰 對以後倍新的践路方面却是必姦的。”

對於無案小解析學基本観念的批郡，以及造

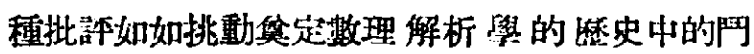

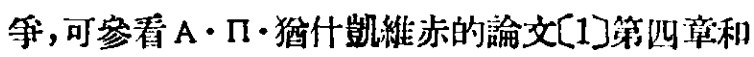
$\mathrm{C} \cdot \mathrm{A} \cdot$ 雅諾夫斯卡雅的論文( $($ 註 $[1]$ ) 


\section{(四)}

蘇聯的學者一一其中包括數學工作者們一 由於參加了社會主義律設的资践、蘇聯人民的偉 大愛國戰爭、和斯大林的五年計亚，日益緊密地国

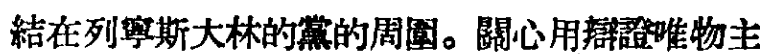
妾哲學的精神集基數學的問題的人起初很少，但 逐桷酸人地攄張起來。研究的問題的內容也窝大 了。在這關節可以注意 $\mathrm{A} \cdot \mathrm{H} \cdot$ 㸝勤莫郭洛夫關於 数祭中理論與實践的論文(註[1])。在羅巴切夫斯 基的第一百五十誕展之際，很多紀念羅氏的論文、 報告、和書籍都論及數學中一系列的主要意識形 態的問題，如批部康德關於空間和㙨何學公理的

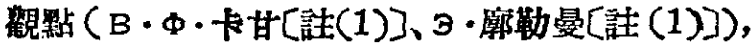
諭近代公理學方法的本質 $(\Pi \cdot \mathrm{C} \cdot$ 阿列克二德洛

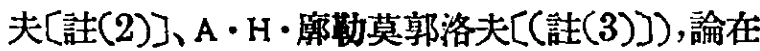
抽象地集立非殹幾里德幾何學中感官直覺所起的 作用問題 $(\mathrm{A} \cdot \mathrm{H} \cdot$ 廓勤莫郭洛夫一九四三年十一 月三日在莫斯科數學會上的報告)。

在一九四四年六月，國立莫斯科大學力學數 學學院組織了盛大的理論會議，討論 ‘認識宇宙的 可能性問題與數學'。在會上䗹取了並討論了 A -

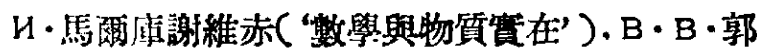
舅别夫 (' $\mathrm{H} \cdot \mathrm{E} \cdot$ 需科夫斯基的哲學觀念', $\mathrm{A} \cdot \mathrm{H}$ ・ 㨯勒莫郭洛夫( “数學和物理學中的空間”)，C A -雅諾夫斯卡雅(“數學中的可證性和真惯性')。,

數學的歷史晢學的與一般方法論的問題在一 系列的論数學史的論文、專書、和報告中也會論 及，例如 M ・ 只・味郭茹基(註[1])批評了資產階級 數學史家們强調拍拉圖做永數學家的領導作用這

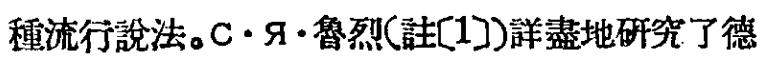
謨克利首的遗作，顯示出來他對於數學的 “原子” 觀點。C・早・魯烈的其他著作(註[2]、[3])討論了 不可分量'的問題，蓝聯帶着處理了數理解析學的

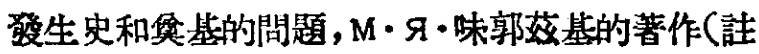

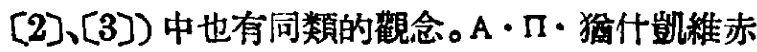
(註[1])討諭了十八世紀數理解析學基的觀念。 在 $H \cdot H \cdot$ 魯金 $($ 註 $[1]), C \cdot$ 魯烈(註[2]、[3]), $\mathrm{A} \cdot \mathrm{H} \cdot$ 廓勒莫郭洛夫(註 $[4]$ )的諭文中, 在牛頓三 百年誕辰之際叙述了和解析學感基的歷史相關的 主浀特徵的一系列問題。数學的意譏形態問題的 處理也見劦:(1)莫斯科大學(一九四四年六月)組 織的會議上的一系列報告中，這些報告部侖迌了葆
聯科學在世界科學和文化的發层中所起的作:用, （2）在俄國大数學家 $\Pi \cdot \Omega \cdot$ 切比謝夫的五十忌店 之際，(3)在十月融會主義革命三十週年之際在莫 斯科大學、莫斯科數學學會、科㲘陀數學研究所 中的報告和講艟中。

在這時候，當反動的資産階粐數理哲學家們 （其中包括着自命是站在唯物主笔和唯心主要中 間的無黨派者) 事宜上站在日更富於侵略性的唯

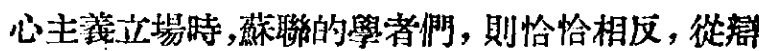

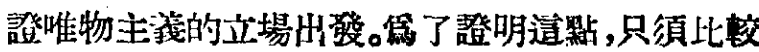

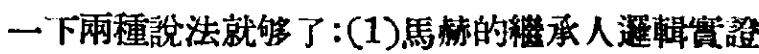

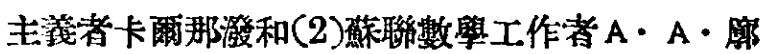
勒莫郭洛去。卡爾那潑認科學理論的可驗登性 是不侾在的, 科學只是“語官”，每㑑人可以依自己 的喜好而選擇或創造自己的浯言。在本質上,卡爾 那潑所謂“語言”是指科學部門的公理建立法,而只 是在建立這種部門時，他提議把在科學的真筫內 容和它表成公理和推演法則的體系形狀的形式表

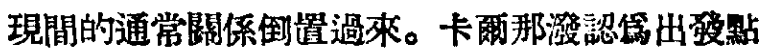
不是员筫的內容，而是任意選澤的一些適意的公 理和從此推演的演繹法则。卡爾娜潑說: “關於”可 驗證性”的問題本身是不存在的; 存在的只不過是 推演的章句法問題。”

反之, $\mathrm{A} \cdot \mathrm{H} \cdot$ 涯勒莫部洛夫認形式的分析 工具之合用, 只是在它相符於筧在的丙容時。而 且，即使是在現在已作好的 “公理系” 中,內容的考 虑也不但不失去意義, 而且繼續着在數學未來弡 展中起主導的作用。例如 $\mathrm{A} \cdot \mathrm{H} \cdot$ 哾勒莫郭洛夫在 幾率論方面作出了最成功的公理化; 他在諭及道 理論時寫道(註[5]): “唔植完全的、数學的、形式 的垣謹性時,郎便是在最一般和抽象的研究中, 也

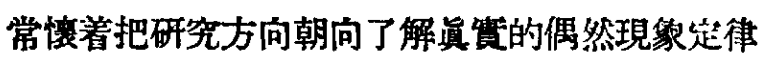

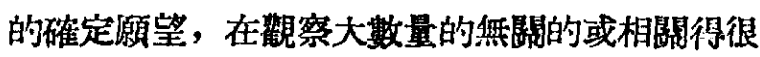
弱的偶然因素的基礎上，生肪嚴格的因果的關聯

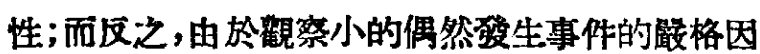
果關聯性的結果得出種種的㙨律分作來。证如在 力學中特别重視的, 乃是在掌握解析的数學工具 之外還有力學的“常識”和力舉的直學的研究者, 我們在研究幾率諭中個品問題的純粹解析學者和 貞正的幾率論專家之間有明確的區别; 後者往往 首先 由描迅的或 “大概的”考應而看出問題的解 來,然後織再去找相應的解析工具。”

$$
\text { 第三期。科學通報 }
$$


(FI)

本文目的在討諭蕉聯䝮者們在數學基礎方伯 的成就。但如果不着重指出本文的基本缺陷,那是

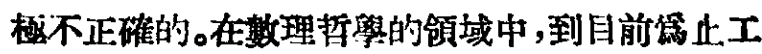
作還很不够，而且很零星。特别基本的乃是在道領

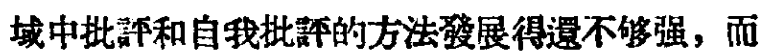
道種方法乃是“我們绫展的動力, 在黨手中的强有 力的武器 ' $(\mathrm{A} \cdot \mathbf{A} \cdot$ 日丹諾夫, 哲舆問題第一卷, 一 九四九年,第二七O頁)。踓然日益獲得更重大的 思想上和政治上的意军，對現代资產階的的理 哲學的反咖唯心主義方向的批呠還没有達到足够 的高度。開於近些年來的工作，只可提及 $几 \cdot \Pi \cdot$ 郭 基集利（晫[1]、[2]、[3]、[4]、[6]）批評荤輯派和 形式主蕂派的著作，和 C - A - 雅諾夫斯卡雅在莫 斯科國立大學所作的一些報告(如 “馬列思想和数 學 '[一九四六年]和 “論科學中的黨性 ‘一九四七 年了)。閣於逼些報告和著作的寬廣的批評討論(造 些屏告賞然可能有問題, 並且還浔有達到馬列主 尊所求的水平),以及提出具有現時性的科學的 和政洽的意学的新戰网性問題, 都是蘇聯的數學 工作者和哲舉工作者們的迫切任移; 而在曾現遭

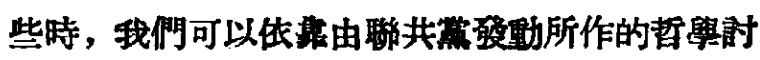
論而得的結果。

\section{原文列基之素考文㳯}

$\mathbf{n} \cdot \mathbf{C} \cdot$ 阿列克三德洛夫:

(1)論與集合論聯繁墢生的数舉新思潮

(数學哲舉論文集,Учпөдгиз (1936)，1420)。

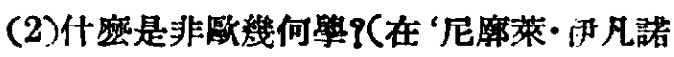
維赤·䍜巴切夫斯基'書中,M.-Л.ГТТИ,, 31 -86 。

$\mathrm{M} \cdot$ 只・味郭茹基:

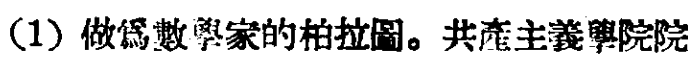
訉，秦十六(1926).192-216。

（2）用馬克思方法論的觀點論数舉史的問題。 自然科學與馬克思主義, 2-3(1930),32 -48 。

(3)約翰·克普勒和他的科學活動。在約翰-克 普勤的書酒涌的立體㙨何學'中, М.ГТТИ (1935), 7-94。

$B \cdot$ B・格利㴌科:

（1）馬克思和阿連瑪的微分觀念。在馬克思主
故嬂下, 然五(1934),79-85。

(2)数學基礎在其湓辰現階段上的危機，(用 列察 諭資本主義社會中科學危機的與馀 的精神)。 $\mathrm{M} \cdot$ 科學與技街陣栈, $5-6,53$ 59 。

(3)数學基礎在其發展現階段上的危機。莫斯 科數理哲學論文集, Учпедгиз (1936),6983 。

$\pi \cdot \Pi \cdot$ 郭其葉利:

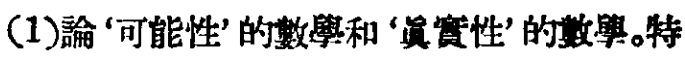
比利斯，蘇聯科學院格魯湾亞分院數罢研 究所專刊,卷穴(1939), 15-96。

(2)論所謂数理論理學中的 ‘內容充繁公理’。

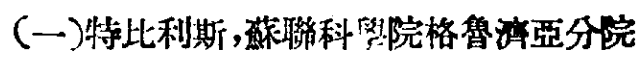
集刊然一 $(1940), 421-428$;(二) 同刊同 然665-672;(三)同刊同然731一738頁;

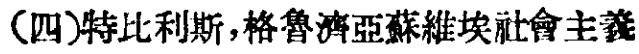
共和國科學睆集刊卷二(1941),51-58。

(3)諭嫩學中存在的概念。(一)格魯流亞蘇維

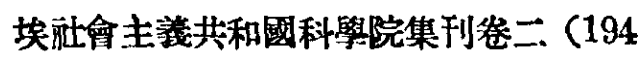
1),881-888;(二)同刊堂: $(1942), 111$ $-118 ;($ 三) 格魯流亞科轝院數學研究所 専刊突十三(1944),153-201。

(4)論數舉中存在的概念。格魯游亞科罢院數 學研究所專刊卷十一 $(1942), 23-51$ 。

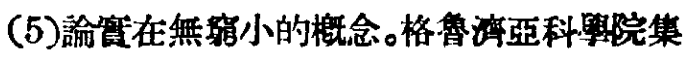
刊管

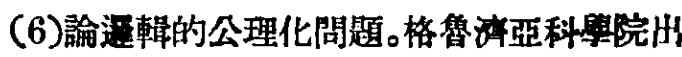
版, (1947), 共86鿓。

(7)馬克思數舉筆記,(1947),1-111。

B・ $\Phi$ ·卡甘：

（1）羅巴切夫斯基。蘇聯科悬院出版，1-344。 $\mathrm{A} \cdot \mathrm{H} \cdot$ 㰾勤莫郭洛夫:

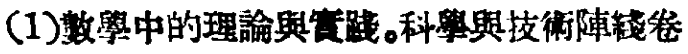
五(1936)。

(2)近世数學。莫斯科数理哲舆諭文集, Учnөnгиз (1926), 7-13。

（3)羅巴切夫斯基和十九世紀的数學思想。在

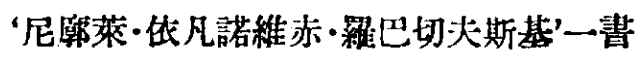
中, М. Л. ГТти $(1943), 87-100$ 。

(4)牛頓與現代數舉思想。在 “莫斯科大學

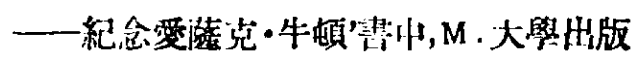


(1946), $47-52$ 。

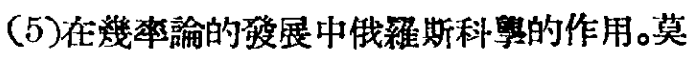

斯科大學科學報告, 91(1947), 47-52。

$A \cdot \Gamma \cdot$ 庫洛什：

(1)當代的代數觀點。莫斯科大學數理哲䁝論 文集,(1936),21-29。

3・斿勒曼 :

（1）䍜巴切夫斯基的偉大思想，(1944), 1一 100 。

C・ ・瀂烈:

（1）古代原子論者的無籍小論。科學院出版， (1935),1-197。

(2)在崩那汝圖拉・卡卭列利的幾何學一書中 卡氏的數學講迅，(1940)，М-Л. ГТТИ。

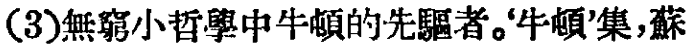
聯科學院出版, (1943)。

$\mathrm{H} \cdot \mathrm{H} \cdot$ 薢金:

(1) 牛頓的楼限諭(哲學研究的嘗試)。“爱限 克·牛頓'潠集, 科學院壮版(1943), 5374 。

B $\cdot \mathrm{H} \cdot$ 莫洛德席:

（1）數學的有效性, (1938), 1-88。

（2)恩格斯論數學發展的起源與因素。自然科 學與馬克思主義(1933),181－203。

$\mathrm{A} \cdot \mathrm{M} \cdot$ 䁈謝爾：

(1)算西特的數理哲學。列案格拉大學數理哲 舉論文集,(1936),97-107。

$\mathrm{A} \cdot \pi \cdot$ 猶什凯維赤:

(1)十八世紀中数擧解析擧基礎的概念。在拉 雜爾・卡爾諾 ‘關於無筑小計算的形而上 學的思考', МлГТТИ(1935),11-76。 $\mathrm{C} \cdot \mathrm{A} \cdot$ 雅諾夫斯卡雅:

(1)做篇無笼小解析學的批評者的米歇勒-羅 勤。自然科學史研究所工作報告，(1947)， $327-346$ 。

(2)現代數理折學的唯心主黉。自然科舉與馬 克思主案, 2-3(1930),10-31。

(3)唯心主㼁與数學。數理哲學論文集, (1936), $55-68$ 。

(4)資盢階敉數理哲學的近代思潮。莫斯科數 理哲罢論文集 (1936),84一-96。

(5)論所謂“經折像化而定義”。同上:108-136。

(6)馬克思數學筆記。書與䇤㡾階級革命, 2 ,
(1933),32-41。

(7)論馬克斯 数學筆記。在馬克思主義旗部 下,卷一(1933), 74一115, 及馬克思主军 與自然科學選集,(1933),138-180。

(8)在共座主義擧院會㼁上的發言: ‘紀 念馬 克思逝世五十週年會議上的科綮材料。 м Л (1934),369-379。

（註一）見阿列克三德洛夫(1),格利洨科(3), 摩勒莫郭洛夫(1)、(2), 庫洛什 (1), 莫洛德什(2)，費謝爾(1)。

（註二）“自然售證法”的第一版是包含德文原 本與 俄譯; ‘數舉筆記’ 則是首先 用俄 文出版的。

(註三)編輯者有 $\Gamma \cdot \mathrm{C} \cdot$ 博格丹, $\mathrm{A} \cdot \mathrm{H} \cdot$ 那希 夫斯卡雅, $\boldsymbol{A} \cdot \mathrm{A} \cdot$ 萊科夫, $\mathrm{C} \cdot \mathrm{A} \cdot$ 雅諾 夫斯卡雅。

(註四)從萊普尼苂與牛頓的“神秘的微分舆’, 經過歐拉與逹朗貝爾的“理性微分學”， 而達到拉格朗日的 '代數徽分學”。

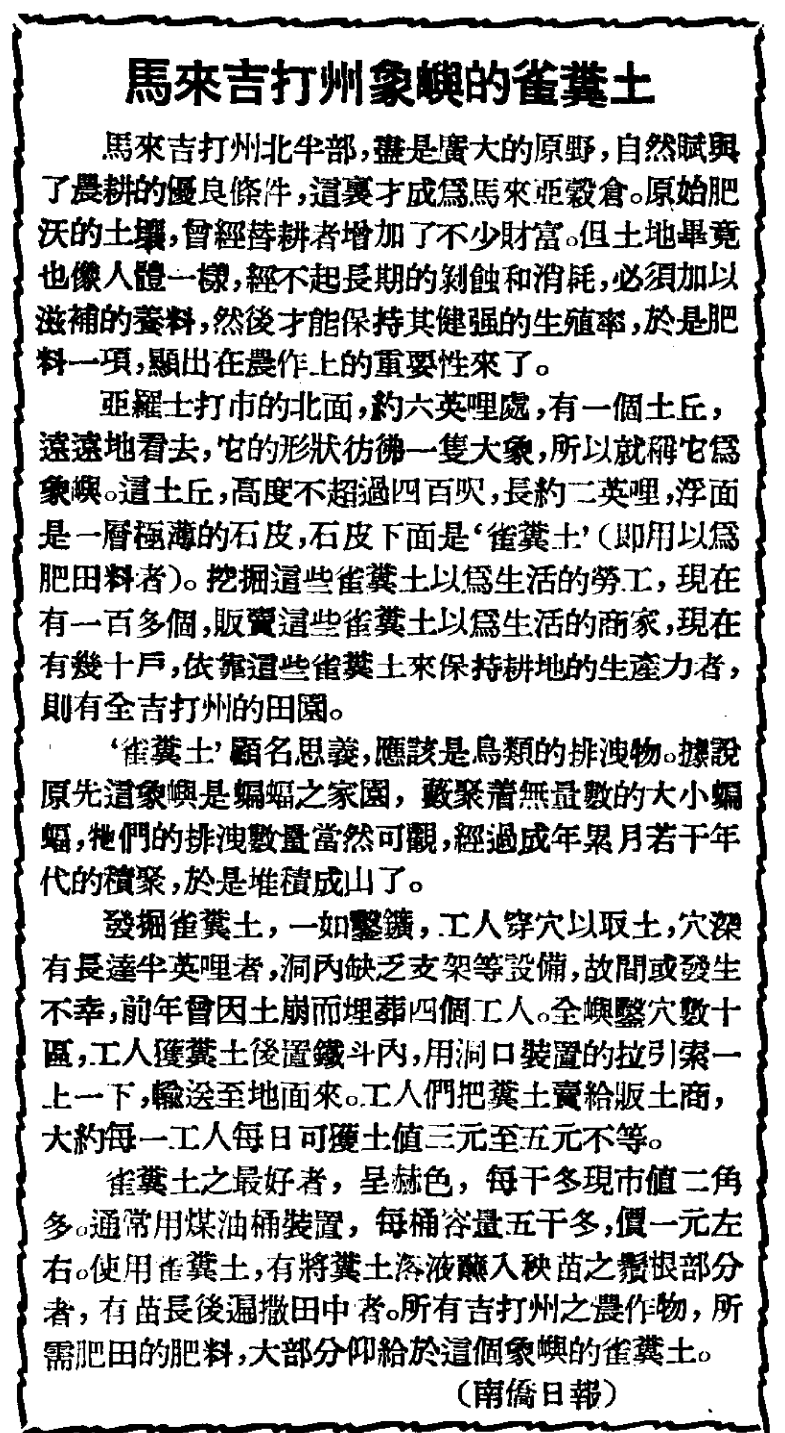

